\title{
Vertical electrical soundings for locating groundwater potential zones in Osmania University Campus, Hyderabad, Telangana State, India
}

\author{
D. Vijay Kumar*, G. Ramadass \\ Department of Geophysics, Osmania University, Hyderabad, Telangana, India
}

Received: 19.09.2015

Revised: 12.10 .2015

Accepted: 10.11 .2015

Published: 10.11.2015

*Address for correspondence:

D. Vijay Kumar,

Department of Geophysics,

Osmania University,

Hyderabad, Telangana, India.

E-mail: ddvkumar7@gmail. com

\begin{abstract}
Based on the resistivity investigations Osmania University Campus, precisely depth and resistivity of subsurface layers were computed; various geoelectric sections along different profiles (I-VIII) were obtained and analyzed. The study area is showing four layered geoelectrical sections, the top soil layer of variable resistivity value between 11.2 and $599 \Omega \mathrm{m}$, and maximum thickness is $0.75-4.45 \mathrm{~m}$. The highly weathered second layer resistivity value varying from 1.72 to $1800 \Omega \mathrm{m}$. Moreover, thickness is $0.12-36.6 \mathrm{~m}$. The third fractured layer indicated by resistivity value 16.3-46074 $\Omega \mathrm{m}$ and thickness is 4.9-87.4 $\mathrm{m}$. The basement that is associated with hard rock and very high resistivities ranging to infinity. The low resistivity with thick overburden and fractured bedrock constitute the aquifer units, and the series of basement undulations identified from the geoelectrical sections are potential points for groundwater locations.
\end{abstract}

KEY WORDS: Aquifer, contamination, geoelectrical section, resistivity, vertical electrical surrounding

\section{INTRODUCTION AND GEOLOGY OF THE AREA}

The Osmania University campus $\left(78^{\circ} 31^{\prime} 00^{\prime \prime}\right.$ E Longitude to $78^{\circ} 32^{\prime} 30^{\prime \prime} \mathrm{E}$ Longitude and $17^{\circ} 23^{\prime} 48^{\prime \prime} \mathrm{N}$ Latitude to $17^{\circ} 25^{\prime} 42^{\prime \prime} \mathrm{N}$ Latitude) is situated in an area of approximately $6.58 \mathrm{~km}^{2}$ (1627.32 acres) [Figure 1] lies in Hyderabad metro politon city (silicon-on-insulator) effectiveness of undulating with a gradual relief toward $\mathrm{N}$-E. The maximum elevation observed is $535 \mathrm{~m}$, and minimum elevation is $503 \mathrm{~m}$ with the mean sea level. Here, three types of granites exist pink, gray and the leucogranites (Balakrishna and Rao, 1961; Sitaramayya, 1968; 1971) and some pegmatite patches traversed by narrow white apatite veins, which intersect each other randomly. The granitic host rocks are intruded at places with doleritic dykes. The general geological section consists of a surgical soil layer underlain by weathered rock, which is in turn followed by the fractured rock at a few places. The basement occurring at an average depth of $15 \mathrm{~m}$ consists of hard impervious granite.

Groundwater occurrence in the hard rock terrain can be vary irregular due to abrupt discontinuity in lithology,

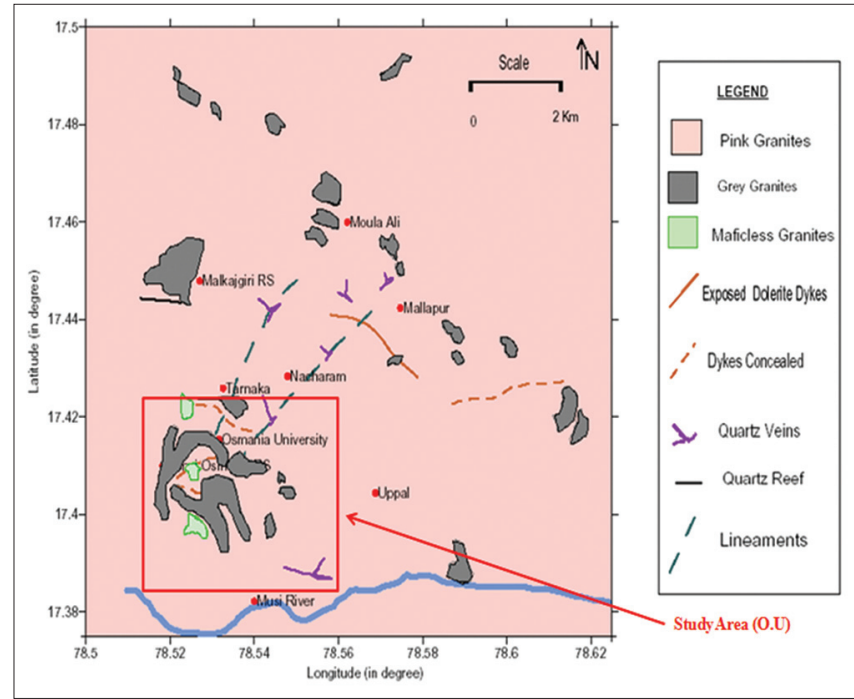

Figure 1: Geology map of the study area (after Udayalaxmi, 2009)

thickness, and electrical properties of the overburden and weathered bedrock (Udayalaxmi and Ramadass, 2013). Many researchers (Kelly and Mares, 1993; Koefed, 1979; Parasnis, 1973; Zohdy, 1964; 1965; 1975) have employed electrical methods of prospecting comprise a wide variety of techniques which utilize different electrical properties and their related phenomena to distinguish between 
different geological formations or to delineate structures. Subsurface characteristics are deduced from measured electrical properties of the earth such as resistivity. Though several geophysical methods are applicable for weathered zone studies under various geological conditions, the electrical methods are especially suited; they can quickly and cheaply demarcate the weathered zones and determine the extent of layers strata. The basic methodology of the electrical method rests on the fact that the resistivity of saturated soil is variable, depending on the layers resistivity and the properties of the geological formations for geological studies (Patangay et al., 2002; Ebrahim et al., 1990; De Lima et al., 1995).

In the present investigation, the objectives of the electrical investigations were to examine the resistivity distribution in the study area, to delineate the structural configuration and geological conditions to a depth of extent and lastly, to estimate and mapping the weathered zone topography and identify aquifers.

\section{DATA ACQUISITION AND ANALYSIS}

A total of 103 vertical electrical soundings (VES), schlumberger configuration with a maximum $\mathrm{AB} / 2$ spacing of $150 \mathrm{~m}$ were carried out with N-S and E-W azimuth at selected locations covering the entire area in the field seasons during the period 2011-2014 [Figure 2].

The resistivity sounding curves obtained from the study area vary of three-layers to four-layers, A- and H-types,

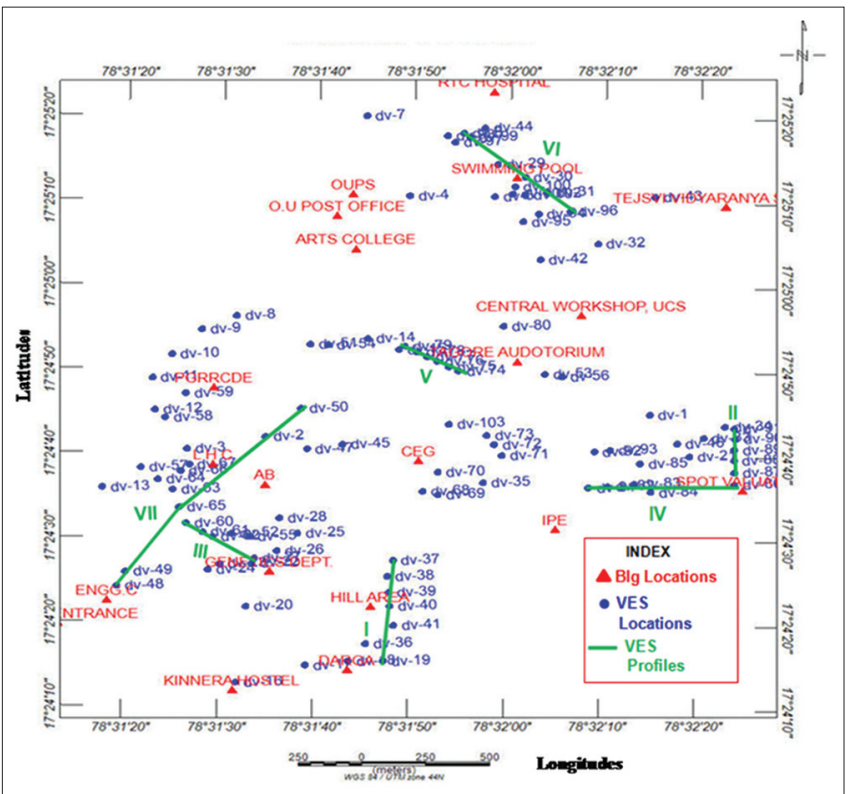

Figure 2: Map of locations of vertical electrical sounding Profiles (I, II, III, IV, V, VI, and VII) in the study area which are characterizing of the basement complex terrain. The H-type is the most dominant curve type in the study area with the particular curve of $46 \%$ similarly, A-type $26 \%$. Four-layers HA-, HK-, and KH-type with percentage curve of $22 \%, 1 \%$, and $5 \%$, respectively. It is observed that the dominant type of curves is the A-type followed by the H-type. Occasionally, wherever fracture and multilayer zones present four layers [Figure 3] type of curves observed. The frequency of the VES curve type shown in Table 1, and a few typicalVES curves are shown in Figure 4.

\section{Quantitative Analysis of VES}

Quantitative interpretation of VES data are performed using curve matching method and inversion IPI2WIN software analysis aims at obtaining the electrical configuration of the subsurface and consisted of generation and examination of the geoelectric section, resistivity contour maps, depth contour maps and contour maps of longitudinal conductance, transverse resistance, anisotropy, and formation resistivity. The various components of the quantitative analysis of electrical data from the study areas are discussed in the following sections. The summary of the interpreted electrical resistivity survey is presented in Table 2; the geoelectric sections reveal that the area is characterized by 3-4 geoelectric subsurface layers.

Table 1: VES curve type frequency in the study area

\begin{tabular}{lc}
\hline Curve type & Frequency \\
\hline A & 26 \\
H & 46 \\
HA & 22 \\
HK & 1 \\
KH & 5 \\
\hline
\end{tabular}

VES: Vertical electrical soundings

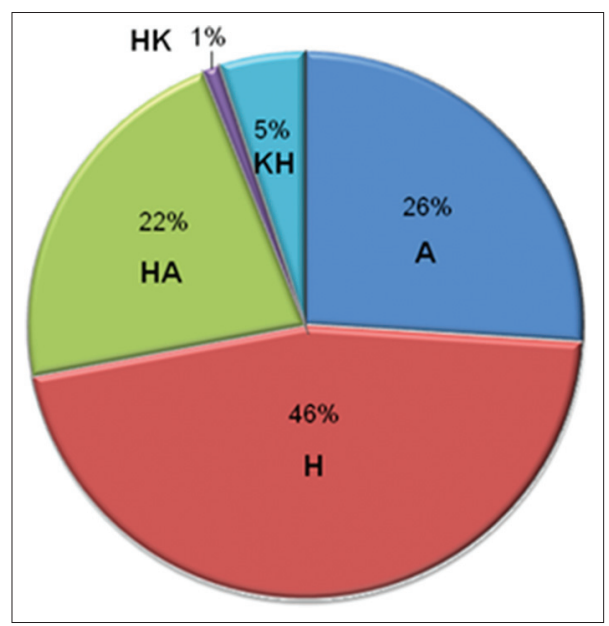

Figure 3: Distribution of curve type in the study area 
SUBSURFACE GEOELECTRIC CONFIGURATION AND RESULTS

The subsurface configuration along chosen seven profiles connecting the $38 \mathrm{VES}$ points were cover all the I, II, III, IV, V, VI, and VII [Figure 2] have been interpreted to evaluate the subsurface geoelectric configuration for study. The vertical section of apparent resistivity in the study area was obtained by contouring the apparent resistivity values plotted (on a logarithmic scale to maintain the reasonable size of inferred section) against $\mathrm{AB} / 2$ separation.

Pseudo-resistivity sections help in deciphering the subsurface resistivity distribution and nature of the

Table 2: Interpreted layer parameters from VES soundings in the study area

\begin{tabular}{|c|c|c|c|c|c|c|c|c|c|c|c|}
\hline VES no. & VES type & VES ID & $\rho_{1}(\Omega m)$ & $\rho_{2}(\Omega m)$ & $\rho_{3}(\Omega m)$ & $\rho_{4}(\Omega m)$ & $h_{1}(m)$ & $\mathrm{h}_{2}(\mathrm{~m})$ & $h_{3}(m)$ & $\mathrm{h}_{4}(\mathrm{~m})$ & $\mathrm{H}(\mathrm{m})$ \\
\hline$d v-1$ & $\mathrm{H}$ & 2 & 191 & 15.1 & 88.4 & 7449 & 1 & 0.12 & 10.3 & - & 11.4 \\
\hline$d v-2$ & $\mathrm{H}$ & 2 & 38.4 & 15.7 & 9999 & - & 1 & 13.6 & - & - & 14.6 \\
\hline$d v-3$ & HA & 3 & 416 & 1.72 & 16.2 & 10,713 & 0.75 & 0.15 & 10.1 & - & 11.0 \\
\hline$d v-4$ & HA & 3 & 126 & 24.7 & 42.1 & 9999 & 0.76 & 0.29 & 13 & - & 14.0 \\
\hline$d v-5$ & $\mathrm{H}$ & 2 & 30.3 & 9.73 & 11,278 & - & 0.75 & 2.52 & - & - & 3.27 \\
\hline$d v-6$ & A & 1 & 11.2 & 278 & 29,520 & - & 0.75 & 25.5 & - & - & 26.2 \\
\hline$d v-7$ & A & 1 & 31.1 & 70 & 23,099 & - & 0.98 & 22.1 & - & - & 23.0 \\
\hline$d v-8$ & $\mathrm{H}$ & 2 & 24.1 & 10.4 & 1678 & - & 0.84 & 7.83 & - & - & 8.67 \\
\hline$d v-9$ & A & 1 & 40 & 86.7 & 196 & - & 1.91 & 37.5 & - & - & 39.4 \\
\hline$d v-10$ & HA & 3 & 157 & 7.94 & 106 & 294 & 1.25 & 0.78 & 29.6 & - & 31.6 \\
\hline$d v-11$ & $\mathrm{H}$ & 2 & 169 & 44 & 9999 & - & 1.14 & 17.6 & - & - & 18.7 \\
\hline$d v-12$ & $\mathrm{H}$ & 2 & 54.2 & 29.8 & 879 & - & 1.3 & 1.23 & - & - & 2.60 \\
\hline$d v-13$ & HA & 3 & 127 & 56.1 & 73.1 & 1771 & 0.75 & 1.74 & 12.1 & - & 14.5 \\
\hline$d v-14$ & HA & 3 & 80.6 & 53.7 & 735 & 4393 & 0.75 & 18.3 & 60.4 & - & 79.4 \\
\hline$d v-15$ & $\mathrm{H}$ & 2 & 290 & 73.9 & 36,452 & - & 3.39 & 31.9 & - & - & 35.2 \\
\hline$d v-16$ & $\mathrm{H}$ & 2 & 290 & 60 & 7349 & - & 1.77 & 18.7 & - & - & 20.47 \\
\hline dv-17 & $\mathrm{H}$ & 2 & 252 & 51.6 & 39,778 & - & 0.98 & 10.6 & - & - & 11.58 \\
\hline dv-18 & A & 1 & 49.1 & 77.6 & 8952 & - & 4.45 & 9.38 & - & - & 13.83 \\
\hline dv-19 & A & 1 & 26.4 & 39.7 & 475 & - & 1.26 & 14.4 & - & - & 15.66 \\
\hline$d v-20$ & A & 1 & 46 & 72.5 & 24,941 & - & 3.56 & 16 & - & - & 19.56 \\
\hline dv-2l & A & 1 & 64.9 & 78.3 & 802 & - & 4.18 & 15.4 & - & - & 19.58 \\
\hline dv-22 & A & 1 & 52.7 & 101 & 6460 & - & 2.42 & 17.3 & - & - & 19.72 \\
\hline dv-23 & $\mathrm{H}$ & 2 & 47.5 & 25.3 & 7259 & - & 2.6 & 3.36 & - & - & 5.96 \\
\hline$d v-24$ & $\mathrm{H}$ & 2 & 134 & 12.5 & 5541 & - & 1.02 & 11.1 & - & - & 12.12 \\
\hline$d v-25$ & HA & 3 & 39.2 & 12.7 & 38.5 & 18007 & 1.04 & 2.12 & 15.1 & - & 18.26 \\
\hline dv-26 & $\mathrm{H}$ & 2 & 69.6 & 39.4 & 25,989 & - & 0.75 & 16.9 & - & - & 17.65 \\
\hline$d v-27$ & $\mathrm{H}$ & 2 & 59.9 & 16.2 & 9999 & - & 0.75 & 8.41 & - & - & 9.17 \\
\hline dv-28 & $\mathrm{H}$ & 2 & 78.2 & 20.1 & 9999 & - & 1 & 9.69 & - & - & 10.69 \\
\hline dv-29 & HA & 3 & 170 & 90.3 & 230 & 1357 & 1.16 & 1.18 & 39 & - & 41.30 \\
\hline dv-30 & HA & 3 & 169 & 47.3 & 187 & 4104 & 2.37 & 2.49 & 57.1 & - & 61.96 \\
\hline dv-31 & $\mathrm{H}$ & 2 & 78.5 & 60.2 & 8886 & - & 1.2 & 3.25 & - & - & 4.45 \\
\hline$d v-32$ & $\mathrm{H}$ & 2 & 204 & 129 & 10,200 & - & 0.75 & 4.46 & - & - & 5.21 \\
\hline$d v-33$ & $\mathrm{H}$ & 2 & 86.2 & 43.6 & 1371 & - & 1.1 & 20.2 & - & - & 21.30 \\
\hline$d v-34$ & HA & 3 & 292 & 105 & 181 & 10101 & 0.75 & 0.94 & 6.85 & - & 8.54 \\
\hline$d v-35$ & A & 1 & 24.4 & 113 & 2740 & - & 2.94 & 14.3 & - & - & 17.24 \\
\hline$d v-36$ & $\mathrm{H}$ & 2 & 129 & 55.9 & 9999 & - & 1.11 & 31.1 & - & - & 32.21 \\
\hline$d v-37$ & $\mathrm{H}$ & 2 & 65 & 21 & 11,201 & - & 1 & 2.18 & - & - & 3.18 \\
\hline$d v-38$ & $\mathrm{H}$ & 2 & 135 & 82.8 & 46,074 & - & 1 & 20 & - & - & 21.00 \\
\hline$d v-39$ & HA & 3 & 108 & 53.9 & 92.6 & 10488 & 1.16 & 2.24 & 4.4 & - & 7.80 \\
\hline $\mathrm{dv}-40$ & $\mathrm{H}$ & 2 & 59.5 & 34.9 & 3719 & - & 1 & 7.53 & - & - & 8.53 \\
\hline$d v-41$ & A & 1 & 34.4 & 69.3 & 21,473 & - & 3.15 & 22.6 & - & - & 25.75 \\
\hline$d v-42$ & A & 1 & 28.1 & 43.3 & 18,741 & - & 1 & 26.8 & - & - & 27.80 \\
\hline$d v-43$ & $\mathrm{H}$ & 2 & 132 & 59.5 & 13,520 & - & 1 & 27.4 & - & - & 28.40 \\
\hline$d v-44$ & HA & 3 & 51.8 & 28.7 & 87.1 & 9586 & 1.31 & 1.73 & 5.56 & - & 8.60 \\
\hline$d v-45$ & $\mathrm{H}$ & 2 & 120 & 38.7 & 10,410 & - & 1.14 & 3.64 & - & - & 4.78 \\
\hline$d v-46$ & $\mathrm{H}$ & 2 & 66.3 & 25.8 & 2041 & - & 1.76 & 2.01 & - & - & 3.77 \\
\hline$d v-47$ & $\mathrm{H}$ & 2 & 236 & 57.8 & 11,269 & - & 1.26 & 10.1 & - & - & 11.36 \\
\hline$d v-48$ & HA & 3 & 31.9 & 20.1 & 80.8 & 22,201 & 1.06 & 3.79 & 14.1 & - & 18.95 \\
\hline$d v-49$ & HA & 3 & 99.2 & 38.7 & 60 & 2317 & 1 & 1.67 & 26.7 & - & 29.37 \\
\hline$d v-50$ & A & 1 & 17.1 & 54.3 & 26,211 & - & 3.84 & 23.2 & - & - & 27.04 \\
\hline$d v-51$ & HA & 3 & 92.2 & 29.7 & 127 & 5974 & 1 & 4.71 & 12.6 & - & 18.31 \\
\hline$d v-52$ & $\mathrm{H}$ & 2 & 65.1 & 34.5 & 1467 & - & 2.37 & 17.8 & - & - & 20.17 \\
\hline$d v-53$ & HA & 3 & 60.2 & 36.1 & 254 & 30,715 & 1.36 & 2.43 & 61.8 & - & 65.59 \\
\hline$d v-54$ & $\mathrm{H}$ & 2 & 74.3 & 22.6 & 12,646 & - & 1.01 & 10.4 & - & - & 11.41 \\
\hline$d v-55$ & $\mathrm{H}$ & 2 & 138 & 51.4 & 38,107 & - & 1.26 & 22.7 & - & - & 23.96 \\
\hline
\end{tabular}


Table 2: (Continued)

\begin{tabular}{|c|c|c|c|c|c|c|c|c|c|c|c|}
\hline VES no. & VES type & VES ID & $\rho_{1}(\Omega m)$ & $\rho_{2}(\Omega m)$ & $\rho_{3}(\Omega m)$ & $\rho_{4}(\Omega m)$ & $h_{1}(m)$ & $h_{2}(m)$ & $\mathrm{h}_{3}(\mathrm{~m})$ & $\mathrm{h}_{4}(\mathrm{~m})$ & $\mathrm{H}(\mathrm{m})$ \\
\hline$d v-56$ & $\mathrm{H}$ & 2 & 92.5 & 59.2 & 4820 & - & 1.34 & 6.87 & - & - & 8.21 \\
\hline$d v-57$ & $\mathrm{HA}$ & 3 & 60.1 & 8.56 & 59.6 & 18,656 & 1.84 & 0.64 & 26.5 & - & 28.98 \\
\hline$d v-58$ & $\mathrm{H}$ & 2 & 195 & 34.1 & 44,598 & - & 0.75 & 10.3 & - & - & 11.05 \\
\hline$d v-59$ & $\mathrm{H}$ & 2 & 114 & 32.4 & 171 & - & 0.94 & 19.8 & - & - & 20.74 \\
\hline$d v-60$ & $\mathrm{KH}$ & 5 & 62.2 & 731 & 50.6 & 9999 & 2.34 & 4.68 & 37.5 & - & 44.52 \\
\hline$d v-61$ & A & 1 & 75.4 & 154 & 9999 & - & 7.46 & 47 & - & - & 54.46 \\
\hline$d v-62$ & $\mathrm{H}$ & 2 & 75.8 & 53.2 & 23,102 & - & 1.74 & 15 & - & - & 16.74 \\
\hline$d v-63$ & A & 1 & 19.3 & 46.6 & 46,224 & - & 0.75 & 6.9 & - & - & 7.65 \\
\hline$d v-64$ & $\mathrm{KH}$ & 5 & 24.7 & 58 & 12.3 & 1749 & 2.11 & 1.62 & 23.8 & - & 27.53 \\
\hline$d v-65$ & $\mathrm{H}$ & 2 & 78.1 & 65.3 & 126 & - & 0.83 & 12.7 & - & - & 13.54 \\
\hline$d v-66$ & $\mathrm{H}$ & 2 & 79.4 & 68.1 & 304 & - & 0.89 & 3.16 & - & - & 4.05 \\
\hline$d v-67$ & $\mathrm{H}$ & 2 & 90.1 & 55.6 & 765 & - & 2.06 & 9.85 & - & - & 11.91 \\
\hline$d v-68$ & A & 1 & 26.6 & 57.5 & 35,941 & - & 1.01 & 14.2 & - & - & 15.21 \\
\hline$d v-69$ & $\mathrm{HK}$ & 4 & 218 & 28.5 & 2557 & 3.6 & 3.95 & 2.48 & 5.04 & - & 11.47 \\
\hline$d v-70$ & $\mathrm{H}$ & 2 & 71.7 & 37.1 & 14,030 & - & 3.45 & 11.6 & - & - & 15.05 \\
\hline$d v-71$ & $\mathrm{HA}$ & 3 & 101 & 43.7 & 295 & 9705 & 1.91 & 2.9 & 87.4 & - & 92.21 \\
\hline$d v-72$ & $\mathrm{H}$ & 2 & 84.6 & 44.2 & 29,659 & - & 1.47 & 18.3 & - & - & 19.77 \\
\hline$d v-73$ & $\mathrm{H}$ & 2 & 599 & 71.3 & 48,014 & - & 2.03 & 11.9 & - & - & 13.93 \\
\hline$d v-74$ & A & 1 & 109 & 1801 & 4157 & - & 0.75 & 6.56 & - & - & 7.31 \\
\hline$d v-75$ & A & 1 & 54.2 & 371 & 8197 & - & 1.06 & 21.2 & - & - & 22.26 \\
\hline$d v-76$ & $\mathrm{KH}$ & 5 & 19.5 & 65.9 & 11.3 & 227 & 0.75 & 0.95 & 6.75 & - & 8.45 \\
\hline$d v-77$ & A & 1 & 52.5 & 196 & 10,783 & - & 3.37 & 54.9 & - & - & 58.27 \\
\hline$d v-78$ & $\mathrm{HA}$ & 3 & 63.1 & 17.5 & 70.2 & 8542 & 0.75 & 4.05 & 10.9 & - & 15.70 \\
\hline$d v-79$ & A & 1 & 60.4 & 151 & 37,374 & - & 0.84 & 8.26 & - & - & 16.72 \\
\hline$d v-80$ & A & 1 & 41.5 & 69.2 & 16,147 & - & 0.75 & 2.55 & - & - & 3.30 \\
\hline$d v-81$ & $\mathrm{HA}$ & 3 & 93.1 & 18.2 & 146 & 12,937 & 0.76 & 1.38 & 7.19 & - & 9.33 \\
\hline$d v-82$ & $\mathrm{HA}$ & 3 & 154 & 17.9 & 108 & 9999 & 0.75 & 0.47 & 46.2 & - & 47.42 \\
\hline$d v-83$ & $\mathrm{H}$ & 2 & 92.8 & 27 & 27,481 & - & 0.87 & 12.1 & - & - & 12.97 \\
\hline$d v-84$ & $\mathrm{HA}$ & 3 & 83 & 5.43 & 57.6 & 4437 & 0.75 & 0.25 & 17.7 & - & 18.70 \\
\hline$d v-85$ & $\mathrm{H}$ & 2 & 62.2 & 35.3 & 54,118 & - & 0.96 & 9.22 & - & - & 10.18 \\
\hline$d v-86$ & $\mathrm{HA}$ & 3 & 39.7 & 30.2 & 41.3 & 14,518 & 0.75 & 8.53 & 23.2 & - & 32.48 \\
\hline$d v-87$ & A & 1 & 38 & 348 & 6.47 & - & 4.1 & 36.6 & - & - & 40.70 \\
\hline$d v-88$ & A & 1 & 58.2 & 205 & 18,873 & - & 3.47 & 62 & - & - & 65.47 \\
\hline$d v-89$ & $\mathrm{HA}$ & 3 & 119 & 34.5 & 150 & 41,128 & 2.42 & 0.69 & 48.8 & - & 51.91 \\
\hline$d v-90$ & A & 1 & 6.21 & 69.2 & 1284 & 4.47 & 1.9 & 10.3 & 17.4 & - & 29.60 \\
\hline$d v-91$ & $\mathrm{H}$ & 2 & 71 & 41.3 & 27,361 & - & 0.80 & 3.89 & - & - & 11.90 \\
\hline$d v-92$ & $\mathrm{KH}$ & 5 & 15.3 & 396 & 10.3 & 10,975 & 0.75 & 0.77 & 2.96 & - & 4.48 \\
\hline$d v-93$ & $\mathrm{H}$ & 2 & 32.1 & 16.7 & 12,950 & - & 4.26 & 3.3 & - & - & 7.56 \\
\hline$d v-94$ & $\mathrm{HA}$ & 3 & 61.8 & 17 & 77.2 & 17,527 & 0.75 & 0.91 & 25.7 & - & 27.36 \\
\hline$d v-95$ & A & 1 & 76.3 & 125 & 845 & - & 0.64 & 16.1 & - & - & 22.57 \\
\hline$d v-96$ & $\mathrm{HA}$ & 3 & 120 & 15.9 & 109 & 1096 & 0.75 & 0.34 & 6.66 & - & 7.75 \\
\hline$d v-97$ & $\mathrm{H}$ & 2 & 30.3 & 16.8 & 391 & - & 0.75 & 4.77 & - & - & 5.52 \\
\hline$d v-98$ & $\mathrm{H}$ & 2 & 31.2 & 21.9 & 145 & - & 0.75 & 4.97 & - & - & 5.72 \\
\hline$d v-99$ & A & 1 & 36.7 & 90.9 & 3633 & - & 1.1 & 8.5 .6 & - & - & 9.670 \\
\hline$d v-100$ & $\mathrm{KH}$ & 5 & 39.6 & 195 & 12.8 & 15,920 & 4.44 & 7.15 & 13.1 & - & 24.69 \\
\hline dv-101 & $\mathrm{H}$ & 2 & 59.4 & 9.96 & 5446 & - & 0.93 & 5.88 & - & - & 15.26 \\
\hline$d v-102$ & A & 1 & 59.6 & 97 & 11,066 & - & 0.61 & 46.4 & - & - & 52.55 \\
\hline$d v-103$ & $\mathrm{H}$ & 2 & 39.4 & 13.8 & 36,421 & - & 0.99 & 2.82 & - & - & 3.81 \\
\hline
\end{tabular}

VES: Vertical electrical soundings

different geological formations present in the region. Edwards (1977) has given the plotting procedures of pseudo-sections for different arrays of measurements, some of which are also described by Udayalaxmi and Ramadass, Apparao and Sharma (1981), and Chakravarthi et al. (2007).

A comprehensive examination of the pseudo-section, geoelectric section (which gives the layer parameters of resistivity and thickness), and geological section helps in understanding the subsurface layer and structural (fault/shear zones, contacts, and joints) configuration.

\section{Profile I}

The Profile I is nearly $630 \mathrm{~m}$ in length to the south of the study area and consists of six VES points $(\mathrm{dv}-37, \mathrm{dv}-$ $38, \mathrm{dv}-39, \mathrm{dv}-40, \mathrm{dv}-41$, and dv-19). It traverses toward the north from nearby Darga (behind the Genetics Department) to behind theVC lodge. Figure 5 a shows the pseudo-resistivity cross section along the N-S Profile I. While the subsurface section below dv-37, dv-38, and dv39 is characterized by high resistivity zones, low resistivities (light blue, dark blue to black tones) corresponding to up to $13 \mathrm{~m}$ spreads, are localized between dv-41 and dv-19. 


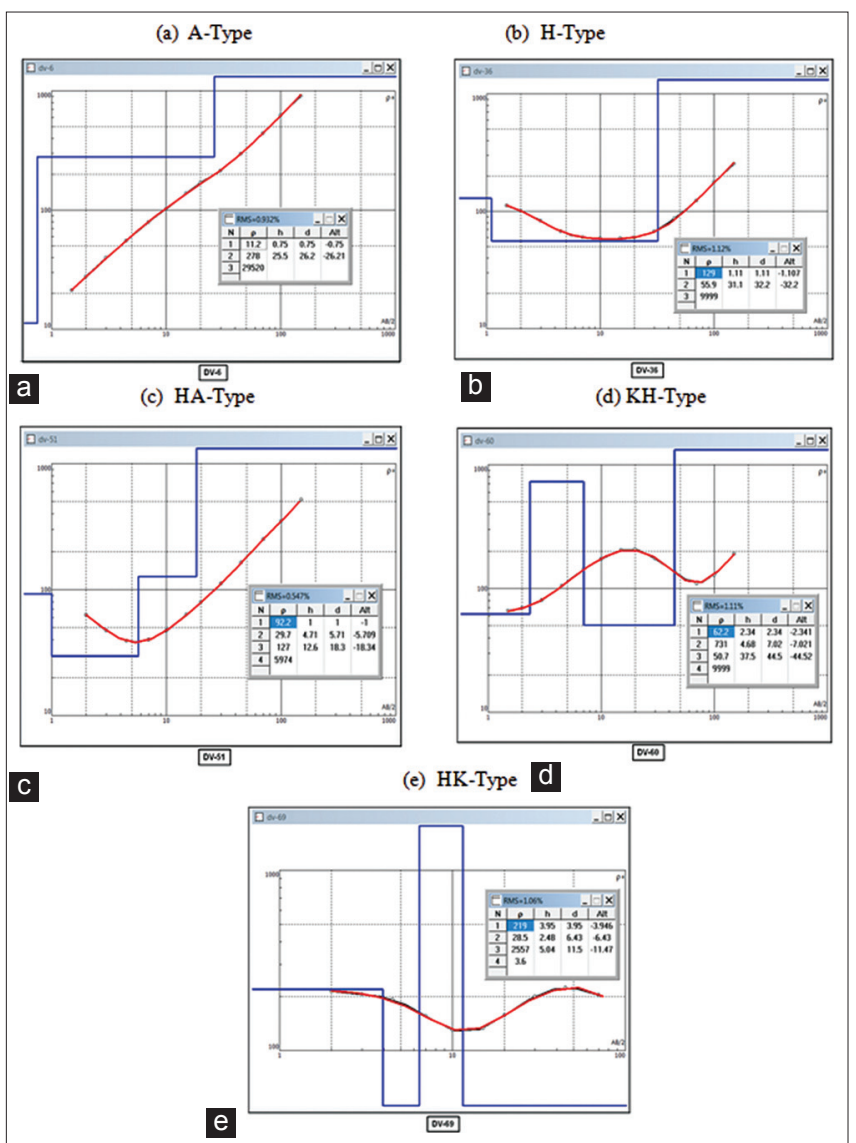

Figure 4: Some typical interpreted vertical electrical soundings curves in the study area, (a) A-type, H-type, (c) HA-type, (d) KH-type, and (e) HK-type

Furthermore, at dv-40, indications of the low $\rho_{\mathrm{a}}$ value $(<30 \Omega \mathrm{m})$ continue to the surface. This low resistivity zone is possibly due to clay with the sand material, which reduces the resistivity values.

Figure $5 \mathrm{~b}$ is the resistivity cross section along Profile I, the geoelectric section [Figure 5c]. Quantitative interpretation of VES data consists of inverting each sounding curve and results in the generation of corresponding geoelectric section that provide composite information on subsurface electrical configuration, layer thickness and resistivity gives the interpreted geoelectrical parameters for the sounding curve. It reveals the substratum conditions that include the nature of the soil/subsurface, and the thickness and depth of occurrence of each layer. It is evident that the top layer, which consists of clayey soil, has resistivity values ranging from 11 to $21 \Omega \mathrm{m}$. The thickness of this layer varies from 1 to $3.15 \mathrm{~m}$.

The resistivity of the second layer [Figure 5b] ranges from 21 to $69.3 \Omega \mathrm{m}$. This layer constitutes the sand zone. In contrast, with the generally low resistivities that characterizes this layer. The thickness [Figure 5c] and

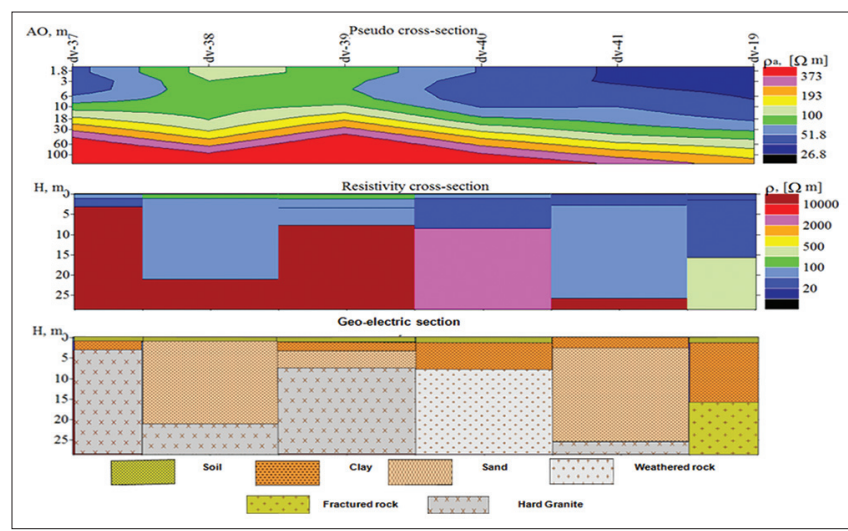

Figure 5: Inferred geoelectrical configurations along the Profile I from nearby Darga (behind the Genetics Department) - to behind the VC Lodge in the study area

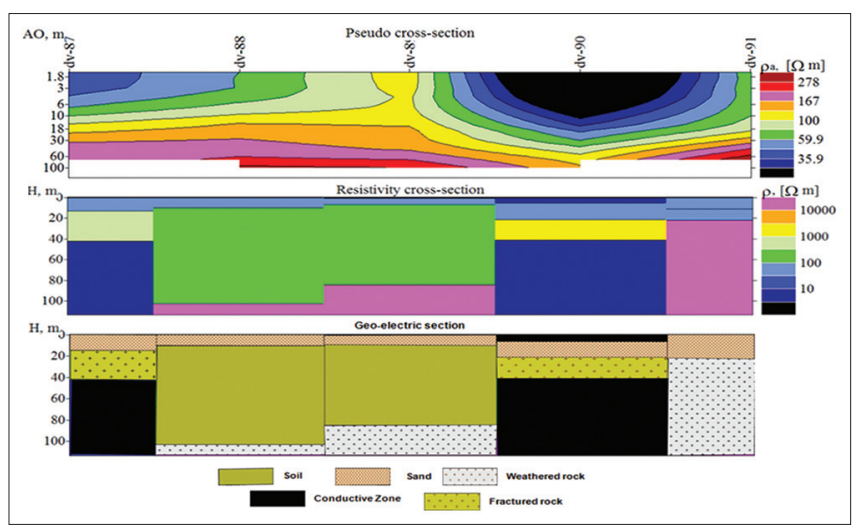

Figure 6: Inferred geoelectrical configurations along the Profile II - old banana garden area adjacent to spot valuation building in the study area

resistivity of the third layer that comprises the fractured basement at dv-40 ranges from 1 to $7.53 \mathrm{~m}$ and 34.9 to $3719 \Omega \mathrm{m}$, respectively.

It is seen that the resistivity of this layer varies from VES (dv-37) toVES (dv-19). High resistivity (up to $46074 \Omega \mathrm{m}$ ) characterizes this layer. Fresh basement forms the fourth layer at dv-39 and consists of unfractured, hard, impermeable rock, with the porosity that is often $<2 \%$.

\section{Profile II}

Profile II is N-S with a trending, $340 \mathrm{~m}$ long profile [Figure 6a] lies to the south of Profile I. It consists of five VES (dv-87, dv-88, dv-89, dv-90, and dv-91) and taken at an old banana garden area adjacent to spot valuation building.

From the pseudo-resistivity section along this profile [Figure 6b], it is seen that a low resistivity zone of 5-11 $\Omega \mathrm{m}$ at VES points $\mathrm{dv}-87$ and $\mathrm{dv}-90$ (black tones in the map) is evident up to a spread corresponding to an $\mathrm{AB} / 2$ separation of 3-7 $\mathrm{m}$ and at $25 \mathrm{~m}$. This low resistivity zone 
is inferred to be clay. On the other hand, high $\rho_{\mathrm{a}}$ values are observed throughout the section, up to a maximum $\mathrm{AB} / 2$ separation of $150 \mathrm{~m}$. The vertical disposition of contours seen at points $\mathrm{dv}-87$, and dv-90 suggests a contact/joint/fault.

Figure $6 \mathrm{~b}$ and $\mathrm{c}$ show the resistivity and geoelectric sections, respectively, along this profile. It is seen that the subsurface in the western part consists of three layers. The resistivity and thickness of the soil vary from 100 to $260 \Omega \mathrm{m}$ and 10 to $85 \mathrm{~m}$, respectively.

The second layer at $\mathrm{dv}-90$ is the low resistivity (50-90 $\Omega \mathrm{m}$ ) weathered layer, within which a pronounced low, corresponding to a clayey/sand zone is evident. As in Profile I, the depth to this layer varies from 1.9 to $10.3 \mathrm{~m}$. Resistivities of $34.5 \Omega \mathrm{m}$ (at $\mathrm{dv}-89$ ) and $41.3 \Omega \mathrm{m}($ at dv-91) are characteristic of the second layer, i.e., weathered zone.

The third layer consisting of fractured granite is variable, both in thickness and resistivity, while the thickness of this layer in the vicinity of dv-88, dv-89, and dv-91 from 20 to $100 \mathrm{~m}$ and the resistivity is $160-200 \Omega \mathrm{m}$. The last layer, hard rock, exhibits higher resistivities ranging to infinity. The depth to the basement topography is uneven, with depth to basement from 100 m below the sounding points.

\section{Profile III}

This NW-SE trending Profile III [Figure 7a] that traverse from High-Tech hostel to Genetics Department running a total length of $400 \mathrm{~m}$ and lies $600 \mathrm{~m}$ to the west of Profile I. The profile consists of five VES (dv-60, dv-61, $\mathrm{dv}-62, \mathrm{dv}-27$, and dv-22). Low apparent resistivity values $\left(\rho_{\mathrm{a}}<20 \Omega \mathrm{m}\right.$; black tones in the figure) are seen below dv-27 sounding point to a depth corresponding to the $10 \mathrm{~m}$ separation. These lows can be attributed to clay strata and/or increase in moisture percentage present at that depth. The resistivity low contours appear to dip toward the southwest, indicating a tectonically disturbed/fractured zone with indications of increased permeability.

The resistivity and interpreted geoelectrical sections [Figure $7 \mathrm{~b}$ and $\mathrm{c}$ ] indicate layer strata consisting of a top layer, which shows both high $(>160 \Omega \mathrm{m}$; in red and yellow tones) and very low resistivities $(<40 \Omega \mathrm{m}$; in black to dark blue tones). However, for the major part, the second layer is characterized by resistivity values of $100-250 \Omega \mathrm{m}$ at dv-61 and dv-22 and a thickness of 7.46-47 $\mathrm{m}$ and $2.42-17.3 \mathrm{~m}$, respectively.

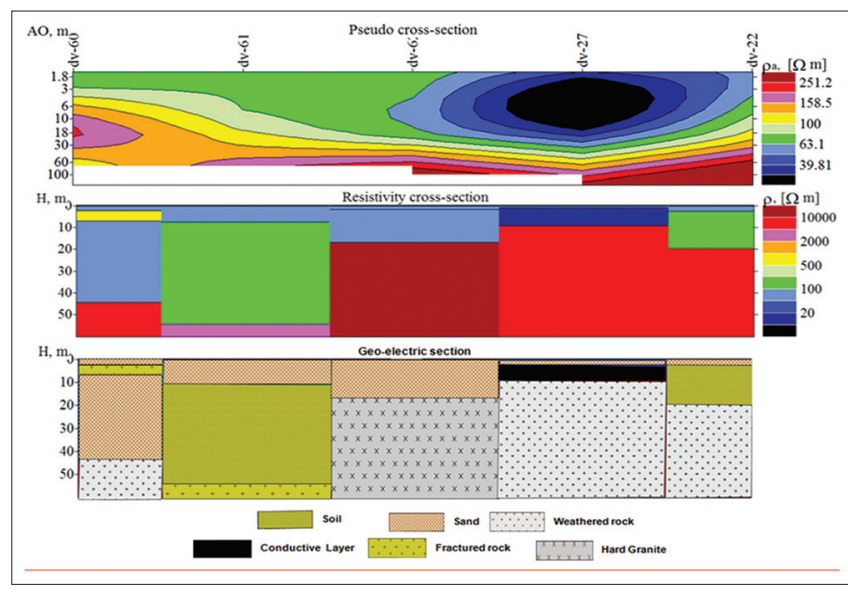

Figure 7: Inferred geoelectrical configurations along the Profile III - from $\mathrm{Hi}$-Tech Hostel to Genetics Department in the study area

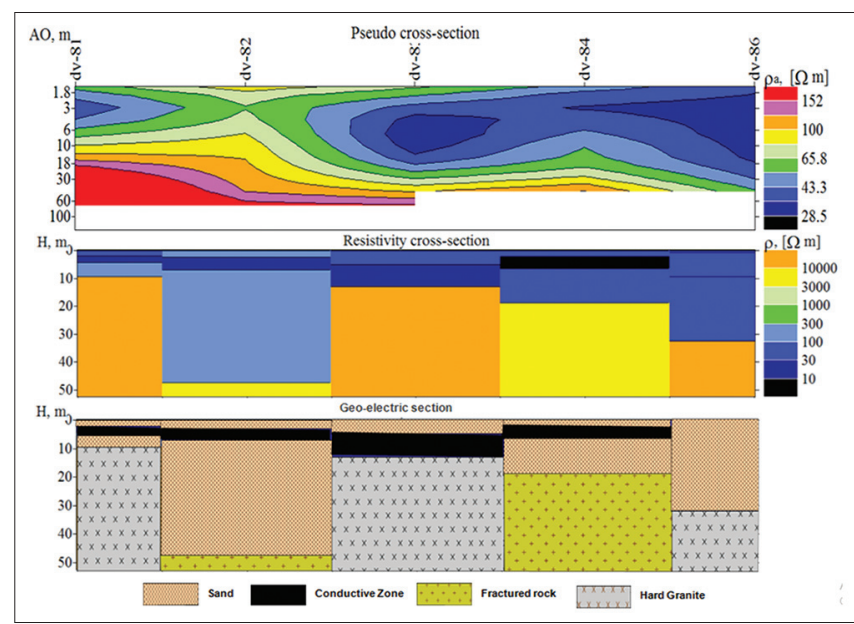

Figure 8: Inferred geoelectrical configurations along the Profile IV from Darga is nearby IPE to spot valuation building in the study area

The third layer comprises fractured rock, which shows resistivities of $100-200 \Omega \mathrm{m}$ at $\mathrm{dv}-60$ and $\mathrm{dv}-61$. The thickness of this layer varies from 2.34 to $4.68 \mathrm{~m}$ and 7.46 to $47 \mathrm{~m}$ forming a thick overburden characterized by high porosity and significant permeability. A weathered zone can be seen within this layer at dv-27 and dv-22 of resistivities ranges from 200 to $251.2 \Omega \mathrm{m}$ at depths of 8.5-15 m, respectively.

\section{Profile IV}

This $520 \mathrm{~m}$ and trending in an E-W direction, Profile IV lies $920 \mathrm{~m}$ toward east from Profile I. Profile IV consists of five VES (dv-81, dv-82, dv-83, dv-84, and $\mathrm{dv}-86)$ and passes from Darga, which is nearby IPE to valuation building. The pseudo-resistivity section along this profile Figure 8 a shows significantly low values at dv-81, dv-82, dv-83, and dv-84 $\left(\rho_{\mathrm{a}}<100 \Omega \mathrm{m}\right)$, discernible from the surface to a depth corresponding to $45 \mathrm{~m}$ separation. 
Figure $8 \mathrm{~b}$ and $\mathrm{c}$ are the resistivity and geoelectric cross sections along with the inferred geology, along the profile. The top layer (soil) has a variable resistivity $10-100 \Omega \mathrm{m}$ and a thickness ranging from 1 to $45 \mathrm{~m}$. The second layer is the weathered layer with very low resistivities $(<10 \Omega \mathrm{m}$; in black to dark blue tones), at dv-81, dv-82, dv-83, and $\mathrm{dv}-84$. Within this layer, low resistivities are observed at depth ranges from 0.75 to $12.1 \mathrm{~m}$.

The third layer comprises fractured rock, which shows resistivities of 65-100 $\Omega \mathrm{m}$. The thickness of this layer varies from 10 to $33 \Omega \mathrm{m}$, forming a thick overburden characterized by high porosity and significant permeability. It is seen that the geoelectric configuration along this profile is similar to that along Profiles II and III; the low resistivity zone in the weathered layer is a clay zone.

\section{Profile V}

Profile V is situated about $910 \mathrm{~m}$ toward the north of Profile I, the $280 \mathrm{~m}$ Profile V with an E-W trend line consists of six VES (dv-74, dv-75, dv-76, dv-77, dv-78, and $d v-79)$. This profile had taken inside the landscape garden quite opposite to "D" Hostel. Figure 9a is the pseudo-resistivity section along this profile.

Figure $9 \mathrm{~b}$ and $\mathrm{c}$ show the resistivity and geoelectric sections with inferred geology. The interpreted subsurface configuration consists of the top layer (silt/sand with clay), the weathered layer and the fractured rock layers that overlie the fractured granite. These layers have respective resistivity ranges of $90-140 \Omega \mathrm{m}$ and layer thickness ranges of 2.2-60 m. The basement occurs overlie of this layer at depths varying between 10 and



Figure 9: Inferred geoelectrical configurations along the profile V-inside the landscape garden quite opposite to 'D' hostel in the study area
$60 \mathrm{~m}$ while the corresponding resistivity ranges from $280 \Omega \mathrm{m}$ to infinity.

\section{Profile VI}

This $1260 \mathrm{~m}$ long, NW-SE trending profile consisting of six VES (d6, dv-99, dv-29, dv-30, dv-31, and dv-96) lies $90 \mathrm{~m}$ to the north of Profile VI. It passes from Post Office, "B" hostel, and swimming pool to professors' quarters. The pseudo-resistivity section along this profile Figure 10a shows a horizontal pattern of contours below a depth corresponding to the $40 \mathrm{~m}$ separation. Resistivity lows are seen at dv-31 and dv-96.

From the resistivity and geoelectric sections [Figure 10b and cl, it is seen that the top layer at dv-6, dv-99, and $\mathrm{dv}-29$, resistivity is very low with significantly conductive zone and at dv-30, dv-31, and dv-96, resistivity values of 50-180 $\Omega \mathrm{m}$. The weathered layer resistivity ranges from 200 to $250 \Omega \mathrm{m}$ (dv-66 and dv-29). Resistivities of 180-230 $\Omega \mathrm{m}$ observed at dv-29, and dv-96 represent fractured granites and resistivities $>400 \Omega \mathrm{m}$ indicate unweathered granites. The layer thickness ranges from 2 to $32 \mathrm{~m}$ for the weathered layer and $10-97 \mathrm{~m}$ for the fractured granites. The bedrock occurs at depths of $25 \mathrm{~m}$ along the profile. It is evident the weathered zone exhibits a greater thickness along this profile as compared to the other profiles.

\section{Profile VII}

Profile VII passing from main entrance of O.U to ladies hostel complex, contains five VES points (dv-48, dv-49, dv-65, dv-2, and dv-50), with a total length of $960 \mathrm{~m}$ and

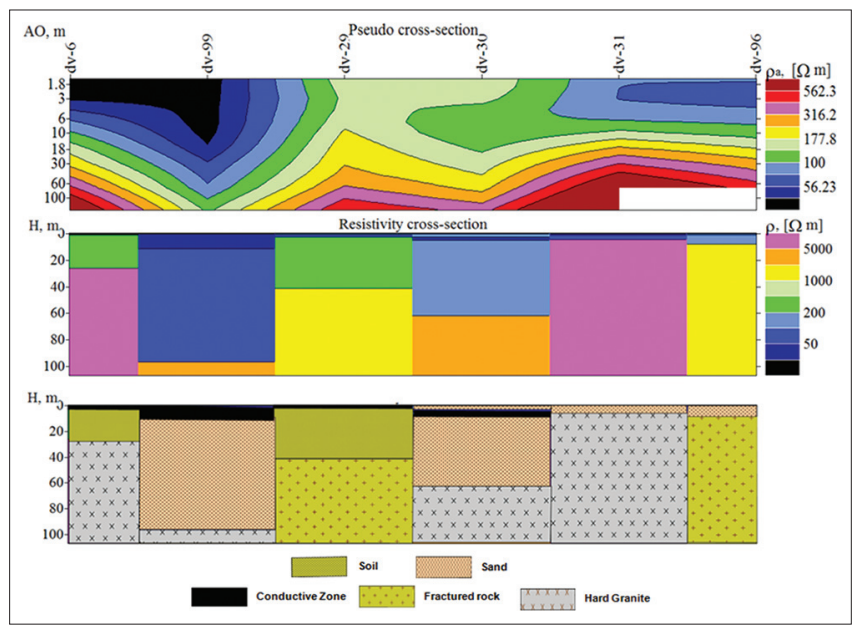

Figure 10: Inferred geoelectrical configurations along the profile $\mathrm{VI}$ - passes from post office, 'B' hostel, and swimming pool to professors quarters in the study area 
situated $760 \mathrm{~m}$ toward west from Profile I. The pseudoresistivity section along this profile [Figure 11a] reveals a resistivity low of $<10 \Omega \mathrm{m}$ (seen in black tones), possibly due to a clay zone in the soil in the vicinity of $\mathrm{dv}-2$. This zone is evident up to an $\mathrm{AB} / 2$ separation of $10 \mathrm{~m}$.

From Figure $11 \mathrm{~b}$ and $\mathrm{c}$ that give the resistivity and geoelectric sections along with the geology along the profile, a four layer subsurface configurations is inferred: Soil (up to $100 \Omega \mathrm{m}$ ), weathered layer (10-50 $\Omega \mathrm{m}$ ) at dv-48,dv-49, dv-65 and dv-50; higher values of about $200 \Omega \mathrm{m}$ at U 65, fractured rock (50-5000 $\Omega \mathrm{m}$ )

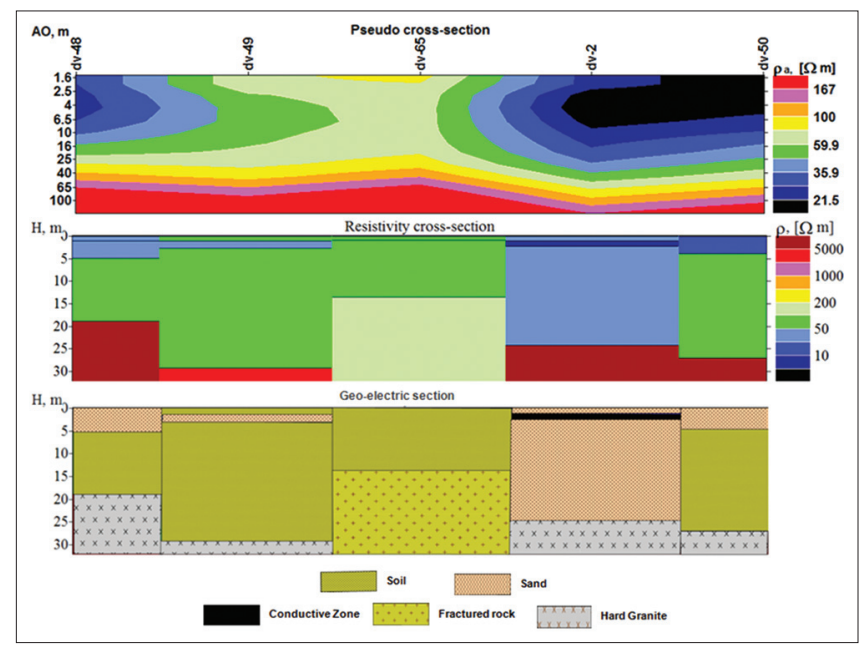

Figure 11: Inferred geoelectrical configurations along the profile VII passing from main entrance of O.U to ladies hostel complex in the study area.

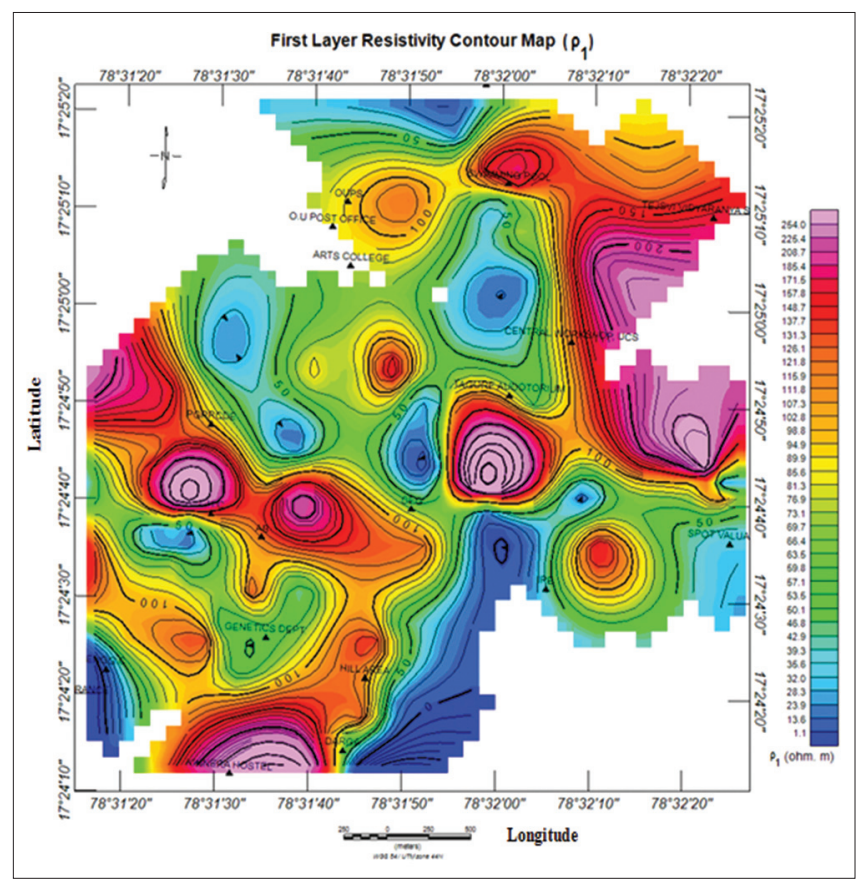

Figure 12: Resistivity contour map of first layer $\left(\rho_{1}\right)$ (contour interval $10 \Omega \mathrm{m})$ and bedrock with respective layer thickness ranges of 0.83-3.5 $\mathrm{m}, 0.70-28 \mathrm{~m}$, and $13 \mathrm{~m}$ - infinity, respectively. The depth to bedrock varies from 18 to $27 \mathrm{~m}$.

\section{CONTOUR MAPS OF LAYER RESISTIVITIES}

The assessment of groundwater potential of a region depends on the estimation of the geometric and hydrologic

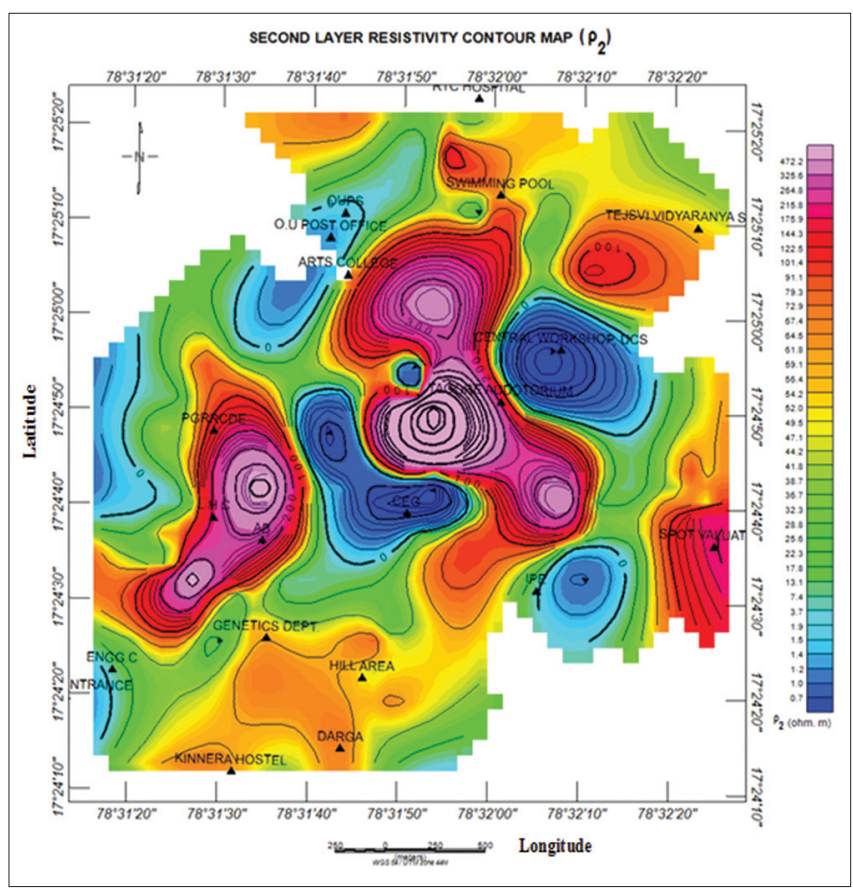

Figure 13: Resistivity contour map of second layer $\left(\rho_{2}\right)$ (contour interval $0.1 \Omega \mathrm{m}$ )

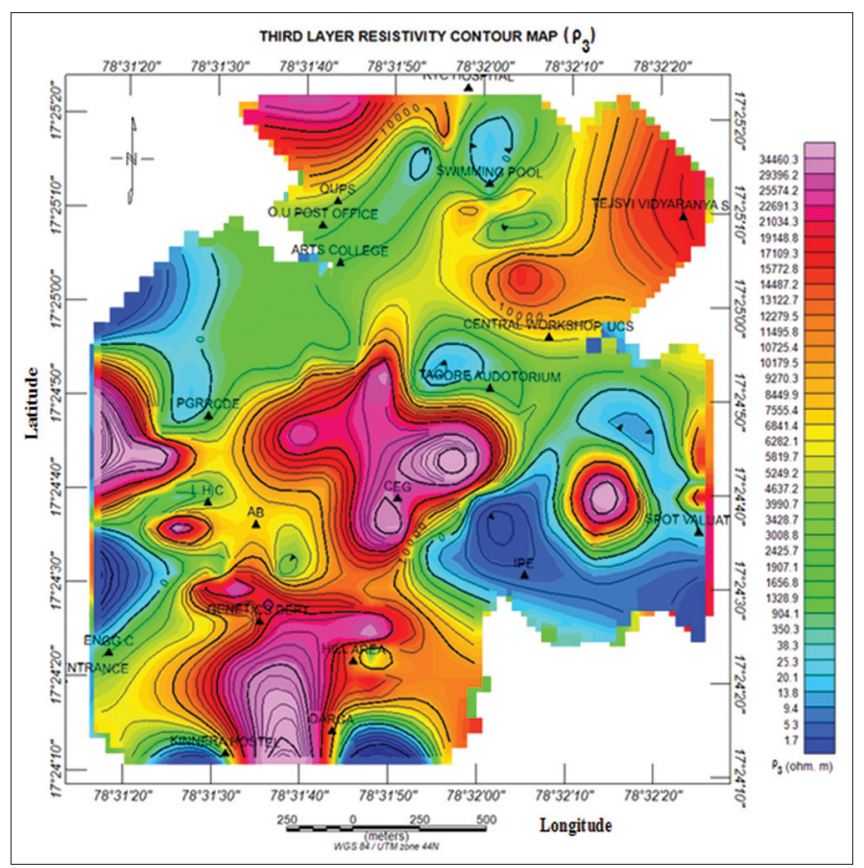

Figure 14: Resistivity contour map of third layer $\left(\rho_{3}\right)$ (contour interval $15 \Omega \mathrm{m})$ 
characteristics of the aquifers. For this purpose, the distribution of geoelectric parameters such as resistivity and thickness of individual layers within the subsurface from a good database. Contour maps of these parameters $-\rho_{1}, \rho_{2}, \rho_{3}$ and $h_{1}, h_{2}, h_{3}, H$ were prepared using a menudriven software package called Oasis Montaj that operates in a Windows environment.

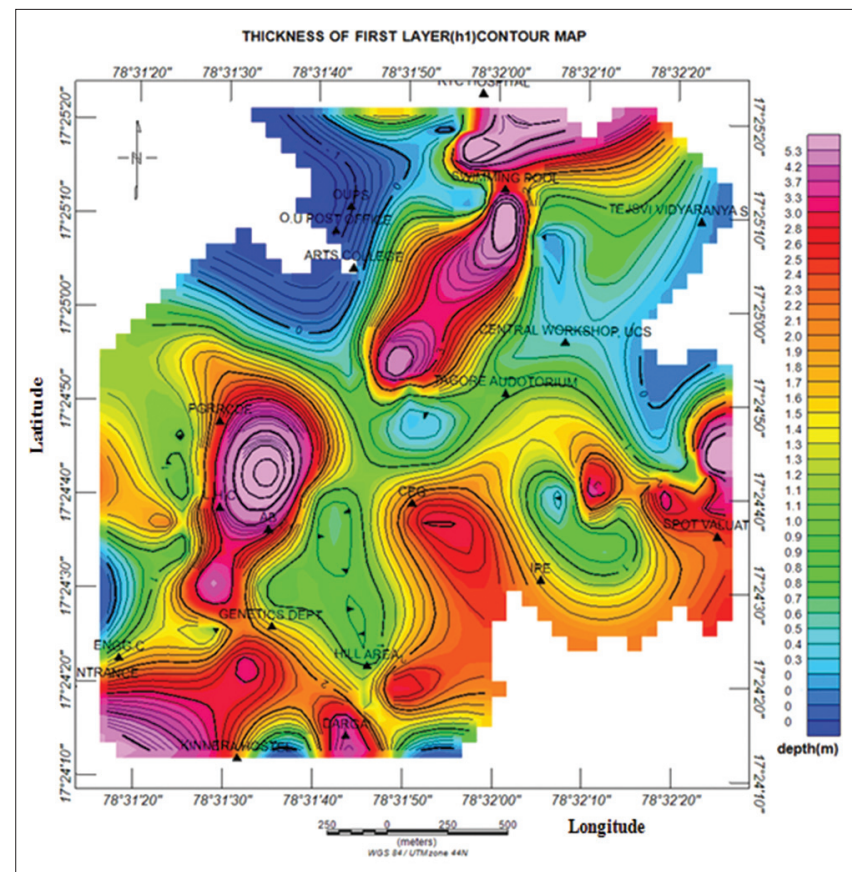

Figure 15: Contour map of first layer $\left(h_{1}\right)$ thickness (contour interval $0.1 \mathrm{~m})$

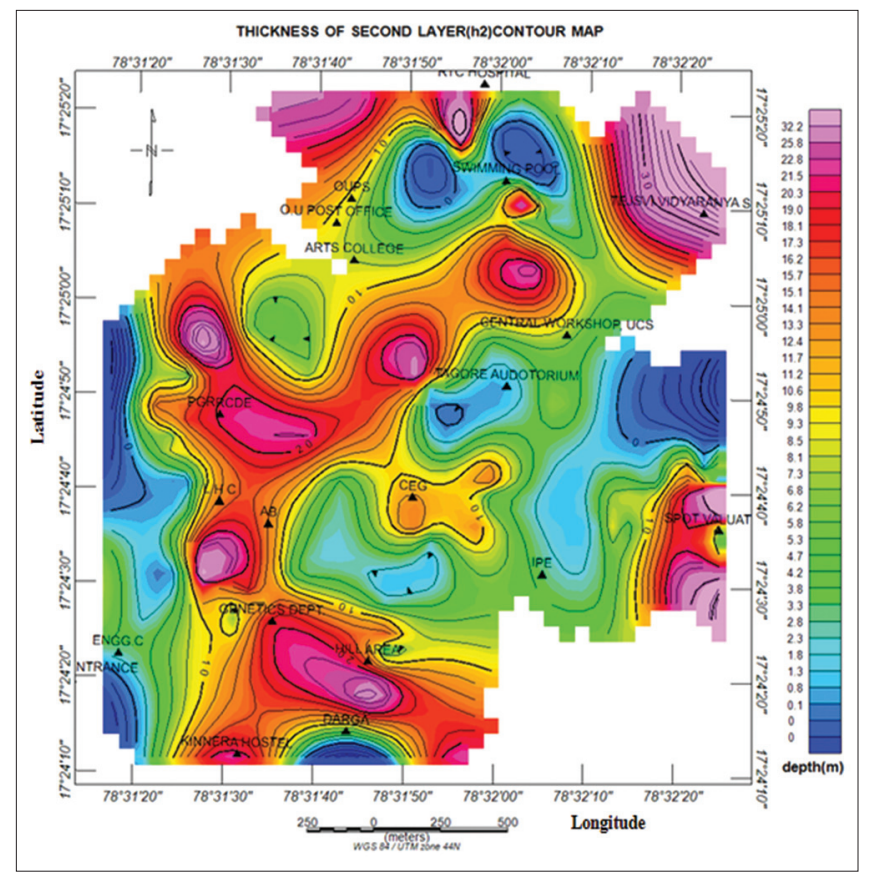

Figure 16: Contour map of second layer $\left(h_{2}\right)$ thickness (contour interval $0.5 \mathrm{~m}$ )

\section{Resistivity of the First Layer $\left(\rho_{1}\right)$}

Figure 12 is a contour map of resistivity of the first layer. Resistivity values range from 1.1 to $300 \Omega \mathrm{m}$. While the average resistivity lies between 4 and $12 \Omega \mathrm{m}$, a resistivity low of $<39 \Omega \mathrm{m}$ is observed near Hi-tech hostel and Darga area which is behind the Genetics Department, CEG, LH complex, Botanical Garden and Spot Valuation building of the study area. Isolated High resistivity zones

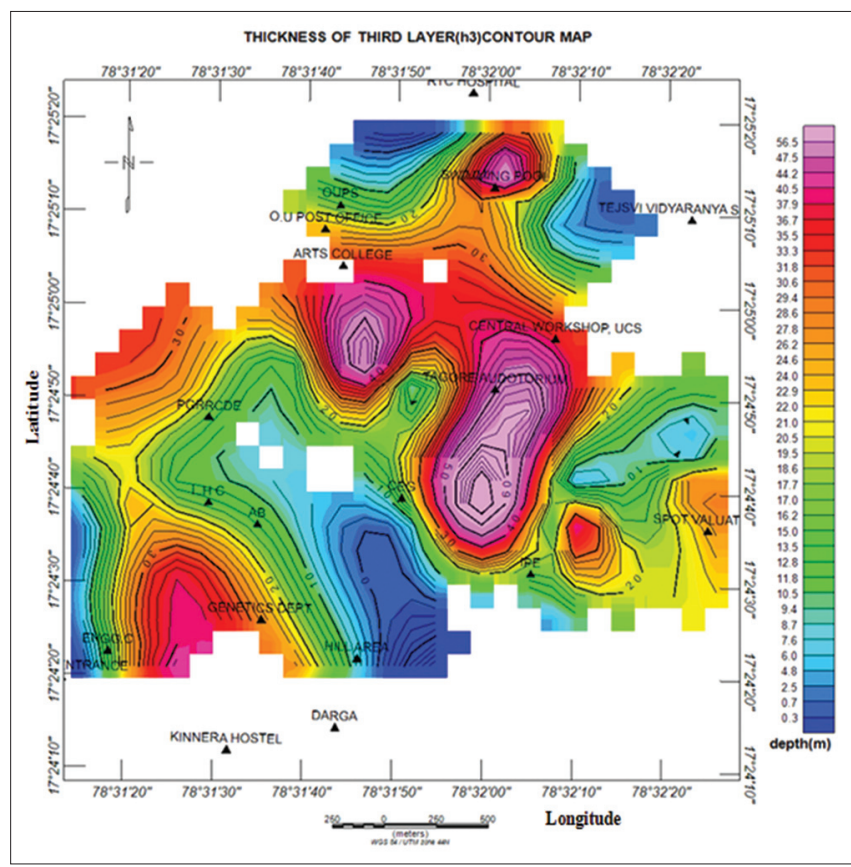

Figure 17: Contour map of third layer $\left(h_{3}\right)$ thickness (contour interval $0.5 \mathrm{~m})$

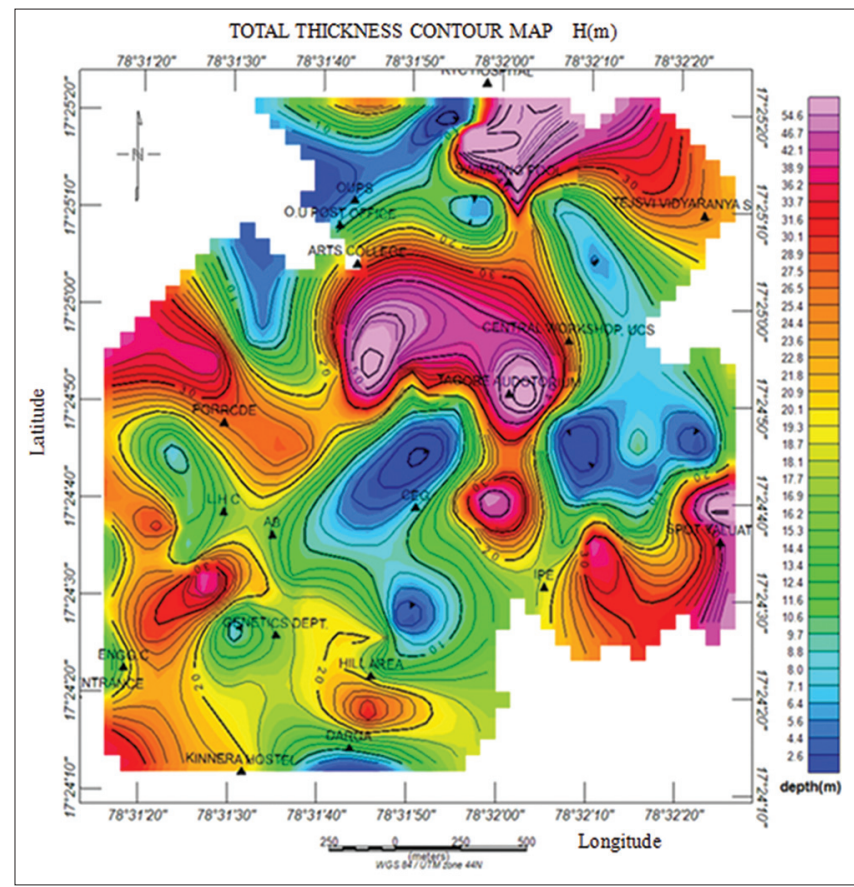

Figure 18: Contour map of total thickness $(\mathrm{H})$ (contour interval $0.8 \mathrm{~m}$ ) 
east and south of the study area and near PGRRCDE (225-260 $\Omega \mathrm{m})$ are noticed.

\section{Resistivity of the Second Layer $\left(\rho_{2}\right)$}

This map [Figure 13] corresponds to the weathered layer of the subsurface where, at places, the water table is also present. By and large, the resistivity $\left(\rho_{2}\right)$ of this layer varies from 0.7 to $13 \Omega \mathrm{m}$ (conductive zone within the weathered layer), except at Ladies Hostel Complex, Administrative Building and Tagore Auditorium (260$500 \Omega \mathrm{m})$. These locations exactly coincide with granitic exposures that trend in N-S and NE-SW direction. Three conspicuous low resistivity zones - at CEG, Botanical Garden and nearby IPE - possibly marked by the presence of clay and/or affected by the sand are also observed.

\section{Resistivity of the Third Layer $\left(\rho_{3}\right)$}

The resistivity of the third layer $\left(\rho_{3}\right)$ varies from 1.7 to 20 , $350 \Omega \mathrm{m}$ [Figure 14]. This layer generally represents the fractured subsurface stratum and constitutes the principal aquifer layer, particularly so opposite to Engineering College, Near PGRRCDE, Swimming pool, Botanical Garden, Old Banana Garden area, Darga, and IPE were markedly low resistivities of 1.7-38 $\Omega \mathrm{m}$ are observed. The rest of the study area is characterized by a relatively high resistivity for this layer.

\section{CONTOUR MAPS OF LAYER THICKNESSES}

\section{Thickness of the First Layer $\left(\mathrm{h}_{1}\right)$}

Figure 15 is a contour map of the thickness of the first geoelectric layer inferred. The contour interval of this map is $0.3 \mathrm{~m}$. It is evident that the thickness of this layer in the region varies from $0.2-4.45 \mathrm{~m}$, with an average thickness of $1.5 \mathrm{~m}$ opposite to Engineering College, Kinnera Hostel, Opposite to CEG, O.U Post Office, and Old Banana Garden are characterized by a low first layer thickness of up to $0.5 \mathrm{~m}$. Relatively greater layer thickness of $1-4.45 \mathrm{~m}$ is observed at the rest of the locations. However, the thickness does not have any bearing on the groundwater potential of the study area.

\section{Thickness of the Second Layer $\left(h_{2}\right)$}

From the contour map of the second layer [Figure 16], it is seen that the configuration of this layer is not uniform; the layer thickness varies from a minimum of $0.1 \mathrm{~m}$ to maximum of $32.2 \mathrm{~m}$. Isolated lows $(0.1-2.8 \mathrm{~m})$ are interspersed with high closures.

\section{Thickness of the Third Layer $\left(h_{3}\right)$}

From Figure 17, contoured with an interval of $2 \mathrm{~m}$ it is seen that the thickness is variable $(1.5-2 \mathrm{~m})$. This layer, corresponding with the fractured layer, constitutes the main aquifer layer in the study area. The greater thickness of this layer is traced at Genetics Department, CEG, Tagore Auditorium, Botanical Garden and Swimming pool. The relatively high thickness zone trends in an N-S and NE-SW direction, Small closures of relatively greater thickness are noticed in the study area.

\section{Total Depth (H) Map}

Figure 18 illustrates the depth to basement, i.e., the sum of the thicknesses of all the overlying layers. Though isolated pockets of $<10 \mathrm{~m}$ depth basement are evident in the area, by and large this value defines the upper limit for depth to the basement while the lower limit is $25 \mathrm{~m}$. These depths correlate well with bore well data [Table 2].

\section{CONCLUSIONS}

Various geoelectric sections along different profiles covering the study area OU campus (I to VII) were obtained and analyzed, showing four layered geoelectrical sections, the top soil layer of variable resistivity value between 11.2 and $599 \Omega \mathrm{m}$, and maximum thickness is $0.75-4.45 \mathrm{~m}$. The highly weathered second layer resistivity value varying from 1.72 to $1800 \Omega \mathrm{m}$ and thickness is 0.12 to $36.6 \mathrm{~m}$. The third fractured layer indicated by resistivity value $16.3-46074 \Omega \mathrm{m}$ and thickness is $4.9-87.4 \mathrm{~m}$. The basement that is associated with hard rock and very high resistivities ranging to infinity.

\section{ACKNOWLEDGMENT}

The authors gratefully acknowledge the financial support extended by the UGC, New Delhi for granting Emeritus fellow.

\section{REFERENCES}

Apparao A, Sharma VS. A modified pseudo depth section as a tool in resistivity and I.P. prospecting, a case history. Geophysical Research Bulletin. Vol. 19. Hyderabad: NGRI; 1981. p. 187-208.

Balakrishna S, Rao MR. Pink and grey granites Hyderabad. Curr Sci 1961;30:264.

Chakravarthi V, Singh SB, Ashok Babu G, Veeraiah B, Stephen J. Delhi-Hardwar ridge and surrounding basement structure - Some inferences from deep resistivity sounding 
measurements. Curr Sci 2007;93:224-230.

De Lima OA, Sato HK, Porsani MJ. Imaging industrial contaminant plumes with resistivity techniques. J Appl Geophys 1995;34:93-108.

Ebrahim AM, Hamburger MW, Bayless ER, Krothe NC. A study of acid mine drainage using earth resistivity measurements. Groundwater 1990;28:361-8.

Edwards LS. A modified pseudo section for resistivity and IP. Geophysics 1977;42:1020-36.

KellyWE, Mares S. Applied Geophysics in Hydrogeological and Engineering Practice. Amsterdam: Elsevier; 1993. p. 289.

Koefed O. Geosounding Principles, I-Resistivity Sounding Measurements. Amsterdam: Elsevier; 1979. p. 276.

Parasnis DS. The Mise-a-la-masse method. Methods in geochemistry and geophysics. Mining Geophysics. $2^{\text {nd }}$ Revised Edition. Vol. 3. Elsevier: New York; 1973. p. 195-202.

Patangay NS, Rao IB, Chary MV, Mathur RR, Keshavulu AS, Srinivas SR. Application of geophysical techniques to trace groundwater pollution due to industrial effluents in the hard rock terrain. J Geophys 2002;XXIII:9-12.

Sitaramayya S. Structure, Petrology and Geochemistry of Granites of Ghatkesar, A.P., and Ph.D.Thesis (unpublished). Hyderabad: Osmania University; 1968.
Sitaramayya S., 1971. The Pyroxene Bearing Granodiorites and Granites of Hyderabad Area, (the Osmania Granites): Quarterly Journal of the Geological, Mining and Metallurgical Society of India, V.43, pp.117-129.

Udayalaxmi G, Ramadass G. VES approach for delineating contaminated groundwater zones in Osmania University and surrounding areas of Greater Hyderabad, A.P., India. Gondwana Geol Mag Nagpur 2009;24:11-8.

Udayalaxmi G, Ramadass G. Environmental studies \& groundwater quality assessment approach through integrated studies in parts of Hyderabad, A.P., India. 2013;6:58-102.

Zohdy AA. Earth resistivity and seismic refraction investigations in Santaclara country, California: Ph.D Dissertations. Ann Asbar, Michigan, USA: Stamford University, Publ. by University Microfilms, A Xerox Company; 1964.

Zohdy AA. The auxiliary point method of electrical sounding interpretation and its relationship to Dar Zarrouk parameters. Geophysics 1965;30:644-60.

Zohdy AA. Automatic interpretation of Schlumberger sounding curves using modified Dar Zarrouk functions. Geological Survey Bulletin 1313E. Washington, DC: Geological Survey Bulletin; 1975. 